\title{
Kinematic analysis of the "attack to the legs" from wrestling: impact of prior judo expertise
}

\author{
Moufti H. ${ }^{\mathrm{ABCD}}$, Arfaoui A. ${ }^{\mathrm{CD}}$ \\ Royal Institute of Management training, National Center of Sports Moulay Rachid, Salé, Morocco
}

Authors' Contribution: A - Study design; B - Data collection; C - Statistical analysis; D - Manuscript Preparation; E - Funds Collection.

\begin{tabular}{|c|c|}
\hline \multicolumn{2}{|l|}{ Abstract } \\
\hline Purpose: & $\begin{array}{l}\text { the framework of motor skill learning and transfer, the objective of the present work is to highlight the } \\
\text { inematics during the technical execution of an "attack to the legs" in wrestling and compare expert wrestlers } \\
\text { vith wrestlers having a prior judo expertise. Moreover, this study aims to evaluate the effects of training on } \\
\text { hese characteristics. }\end{array}$ \\
\hline Material: & $\begin{array}{l}0 \text { male subjects were divided in two groups of five: the first group contains wrestlers with at least } 7 \text { years of } \\
\text { restling practice. The second group contains two-year practice wrestlers with } 5 \text {-year prior judo experience. } \\
\text { ubjects had to perform a movement of attack towards the opponent's legs (free style wrestling). A three- } \\
\text { imensional analysis was carried, the displacement of seven passive markers placed over anatomical points } \\
\text { las quantified ( } 3-\mathrm{D} \text { motion analyzer, sampling rate } 25 \mathrm{~Hz} \text { ). The following parameters were calculated: } \\
\text { ngulation of the hip and of the knee, velocity and acceleration of the shoulder and of the wrist. The } \\
\text { xperiment was conducted twice: at the beginning of the wrestling training schedule and ten weeks later. }\end{array}$ \\
\hline Results: & $\begin{array}{l}\text { Results showed marked differences between the two groups in the kinematics of the movement. These } \\
\text { results suggest interference between prior automatisms and learning new skill. The prior experience in } \\
\text { judo would have influenced posture in this group. In the framework of skill transfer and dexterity, this study } \\
\text { appears promising to investigate the processes involved in this motor control. }\end{array}$ \\
\hline Conclusions: & $\begin{array}{l}\text { Although wrestling and judo are two sport disciplines that belong to the same group of combat sport, this } \\
\text { work underlines the specificity of learning and indicates that acquisition of motor abilities in a speciality is not } \\
\text { transferred inevitably in a positive way in another speciality of the same group. }\end{array}$ \\
\hline Keyv & Transfer of learning, motor skill, postural control, wrestling, judo. \\
\hline
\end{tabular}

\section{Introduction}

Combative sports with grasping are characterized by the existence of some common technical bases [1], which generate a comparison among the various disciplines based on these similarities. Athletic learning and training allow sportsmen to acquire new motor abilities [2]. However, sensory integration mechanisms and gesture automation differ according to the specificities of practiced sport $[3,4]$. Former studies showed that sport training plays a significant role in postural control through the acquisition of new motor skills suitable for the nature of the activity [5]. Besides, sport training could support the choice of the strategy of posturo-kinetic coordinations adapted to the realization of the new motor task [6]. The perfect realization of every gesture could not be considered without the principal bases of any sport learning. These bases are the acquisition of particular motor program, the automatisation of the gesture through its repetition, and the optimal treatment of sensory information. The latter one is performed through the development of the treatment of specific sensory entries of the task [7].

However, there is a fundamental problem: can sport training have a general influence on activities other than those practiced during this training or are skills built by specific training? Wrestling and most other sports depend on a specific body form for the effectiveness of their techniques [8]. The ability to attack or to defend against an attack under any circumstance depends largely

(C) Moufti H., Arfaoui A., 2019

doi:10.15561/18189172.2019.0103 upon the production of specific movement. It is frequent that judokas and wrestlers move from one practice to another, but this transition is sometimes accompanied by difficulties in learning this new skill while learning to master technical movements $[9,10]$.

Hypothesis: While learning a new skill in a certain combative sport, prior practice in another combative sport would have an influence on performing this skill. Common posturo-kinetic control mechanisms would be responsible for this influence.

Purpose: In the framework of motor skill learning and transfer, the objective of the present work is to highlight the kinematics during the technical execution of an "attack to the legs" in wrestling, and compare expert wrestlers with wrestlers having a prior judo expertise. Moreover, this study aims to evaluate the effects of training on these characteristics.

\section{Material and Methods}

Participants: 10 male subjects were divided in two groups of five: the first group contains wrestlers with at least 7 years of wrestling practice (called "wrestlers") (mean age $22.8 \pm 3.6$ years, height $178 \pm 10 \mathrm{~cm}$, weight: $82.8 \pm 27.9 \mathrm{~kg}$ ). The second group contains two-year practice wrestlers with 5-year prior judo experience (called "wrestler-judokas") (mean: age $22.2 \pm 2.7$, height $175 \pm 62 \mathrm{~cm}$, weight: $70.6 \pm 12.2 \mathrm{~kg}$ ). The average height and weight do not differ significantly between the two groups.

Research Design: Subjects had to perform a 
movement of attack towards the opponent's legs (free style wrestling). The opponent was represented by a support made up of a square base ( $2 \mathrm{~cm}$ height) on which was fixed a vertical bar surrounded by foam $120 \mathrm{~cm}$ high and $10 \mathrm{~cm}$ wide.

The purpose of the movement of attack to the legs is the simultaneous seizure of the two legs and the imbalance of the opponent backwards.

Seven passive landmarks were placed over anatomical points to record the movement of the body: shoulder (acromion), elbow (olecranon), wrist (styloid process of the ulna), hip (anterior superior iliac spine), knee (fibular head), ankle (lateral malleoles) and head (temple).

The experiment was conducted twice (first test T1 and second test T2) with a 10 week intervening period of wrestling training. All subjects had the same training schedule.

Movements were recorded and analysed using the 3-D vision system -Biometrics- (sampling rate $25 \mathrm{~Hz}$ )

Statistical Analysis: The analysis deals with the first two phases of this technical movement: Guard and departure towards the legs and arrival and seizure of the mast. The following parameters were calculated:

The angle $(\alpha)$ determined by the head and the trunk and the angle of the hip ( $\beta$ ), the value at the beginning of the movement $(\alpha 1 ; \beta 1)$, the minimal value of this angle $(\alpha 2 ; \beta 2)$ and its value at the end of the movement $(\alpha 3 ; \beta 3)$ when the subject seizes the support with the hand.

For the angle of the knee $(\gamma)$, the value at the beginning of the movement $(\gamma 1)$, the value corresponding to the angle ( $\beta 2)$ at the same moment $(\gamma 2)$ and the value at the end of the analyzed movement $(\gamma 3)$.

For speed and acceleration of the various markers, we recorded the values corresponding to the maximum and the times at which they appeared. We calculated the averages of the two trials for each parameter. For the analysis, we used nonparametric tests, Mann-Whitney's tests to compare the results of wrestlers and wrestlersjudokas. The evolution in (through?) time between the two tests (T1 and T2) was analyzed using Wilcoxon's test.

\section{Results}

When the subjects were tested for the first time, the angles calculated are closer among pure wrestlers than among the judokas. This difference reaches the significance level with regard to the angle of the knee at the beginning of the movement $(\gamma 1)$, the minimal value of the angle of the hip ( $\beta 2)$, the angle of the hip at the end of the analyzed sequence ( $\beta 3$ ) (Mann-Whitney test: $U=1$, $\mathrm{p}<0.02 ; \mathrm{U}=1, \mathrm{p}<0.02 ; \mathrm{U}=1, \mathrm{p}<0.02$ respectively).

The results of the evaluation carried out during the second test (T2), ten weeks after the first, at the end of the period of training are relatively similar to those of the previous test, the posture of the wrestlers seems more "crouched" compared with the movement realized by the wrestler-judokas. The wrestlers tend to keep the trunk more tilted $(U=4 ; 0.05<p<0.10)$ at the beginning of the movement. Their leg is more bent at the beginning $(\gamma 1)$ and the trunk on arrival is more brought back towards the leg than that of the judokas $(\beta 3)(U=2, p<0.05 ; U=2$, $\mathrm{p}<0.05$ respectively). In a general way, the wrestlers adopt a postural attitude consisting of a lowering of the centre of gravity more significant than that of the wrestler-judokas from the start and a more marked slope of the trunk on the leg.

Among wrestlers, the results show a great stability of time regarding the parameters taken into account (Wilcoxon test, NS). In the wrestler-judokas, it is noticed that the angular values seem lower on average during the second test, the statistical analysis however states that these differences are not significant for any estimated parameter.

Maximum speeds (Table.1) for both the first and the second test, of the various landmarks seem to be overall identical for the wrestlers and the wrestler-judokas. Between the first and the second test, these maxima do not evolve to a significant degree (Wilcoxon test, NS) among wrestlers, for the wrestler-judokas the difference is significant on the level of the knee (landmark 5) and the head (landmark7) (Wilcoxon test, $\mathrm{Z}=1.752,0.05<\mathrm{p}<0.10$; $\mathrm{Z}=2.022, \mathrm{p}<0.05$ respectivly). In the second test, these subjects seem to improve the speed of movement execution.

Maximum speed is not reached more quickly (MannWhiteny test, NS) during the two tests, except for wrestlers subjects at the level of the head in the first test (Mann-Whitney test, $\mathrm{U}=3, \mathrm{p}<0.05$ ).

Compared to the initial test, speed is reached more quickly during the second test, for the shoulder as for the wrist (test of Wilcoxon: $Z=-2,023, p<0,05 ; Z=-2,060$, $\mathrm{p}<0,05$ respectively) in wrestlers. For the wrestlerjudokas, it is at the ankle level that the difference is significant (Wilcoxon test: $Z=2,022, p<0,05$ ).

Given the illustrated results (table.2), it seems that the peak of acceleration among wrestlers is higher than for the judokas during the first test. Nevertheless, this

Table 1. Peaks of speeds $(\mathrm{m} / \mathrm{s})$ on the level of the various landmarks for the wrestlers and the wre-judokas during the first and the second test. Average values and standard deviations

\begin{tabular}{|c|c|c|c|c|c|c|c|c|c|c|c|c|c|c|}
\hline \multirow{2}{*}{ Group } & \multicolumn{2}{|c|}{ t Landmark 1} & \multicolumn{2}{|c|}{ Landmark 2} & \multicolumn{2}{|c|}{ Landmark 3} & \multicolumn{2}{|c|}{ Landmark 4} & \multicolumn{2}{|c|}{ Landmark 5} & \multicolumn{2}{|c|}{ Landmark 6} & \multicolumn{2}{|c|}{ Landmark 7} \\
\hline & T1 & T2 & T1 & $\mathrm{T} 2$ & T1 & T2 & T1 & T2 & T1 & T2 & T1 & T2 & T1 & T2 \\
\hline Wrestlers & $\begin{array}{l}2.135 \\
( \pm 0.46)\end{array}$ & $\begin{array}{l}1.681 \\
( \pm 0.54)\end{array}$ & $\begin{array}{l}2.345 \\
( \pm 0.41)\end{array}$ & $\begin{array}{l}1.865 \\
( \pm 0.24)\end{array}$ & $\begin{array}{l}2.729 \\
( \pm 0.62)\end{array}$ & $\begin{array}{l}2.223 \\
( \pm 0.41)\end{array}$ & & & & & $\begin{array}{l}00 \\
.4)\end{array}$ & & & \\
\hline $\begin{array}{l}\text { Wrestlers- } \\
\text { judokas }\end{array}$ & $\begin{array}{l}1.688 \\
( \pm 0.43)\end{array}$ & $\begin{array}{l}1.727 \\
( \pm 0.18)\end{array}$ & $\begin{array}{l}1.875 \\
( \pm 0.35)\end{array}$ & $\begin{array}{l}2.115 \\
( \pm 0.14)\end{array}$ & $\begin{array}{l}2.575 \\
( \pm 0.8)\end{array}$ & $\begin{array}{l}2.753 \\
( \pm 0.8)\end{array}$ & $\begin{array}{l}1.444 \\
( \pm 0.34)\end{array}$ & $\begin{array}{l}1.813 \\
( \pm 0.49)\end{array}$ & $\begin{array}{l}1.359 \\
( \pm 0.81)\end{array}$ & $\begin{array}{l}1.925 \\
( \pm 1.1)\end{array}$ & $\begin{array}{l}1.529 \\
( \pm 1.84)\end{array}$ & & & \\
\hline
\end{tabular}


Table 2. Peaks of acceleration $\left(\mathrm{m} / \mathrm{s}^{2}\right)$ on the level of the various landmarks for the wrestlers and the wre-judokas during the first and the second test. Average values and standard deviations

\begin{tabular}{|c|c|c|c|c|c|c|c|c|c|c|c|c|c|c|}
\hline \multirow{2}{*}{ Group } & \multicolumn{2}{|c|}{ st Landmark 1} & \multicolumn{2}{|c|}{ Landmark2 } & \multicolumn{2}{|c|}{ Landmark 3} & \multicolumn{2}{|c|}{ Landmark 4} & \multicolumn{2}{|c|}{ Landmark 5} & \multicolumn{2}{|c|}{ Landmark 6} & \multicolumn{2}{|c|}{ Landmark 7} \\
\hline & T1 & T2 & T1 & & & & & & & & & & & \\
\hline Vrestlers & & & & & & & & & & & & & & \\
\hline $\begin{array}{l}\text { res } \\
\text { udd }\end{array}$ & & & & & & & & & & & & & & \\
\hline
\end{tabular}

difference is statistically significant only for the shoulder (landmark 1) (Mann-Whitney test, $U=3, p<0.05$ ). During the second test, the subjects of the two groups present similar maximum accelerations. For the wrestler-judokas, as with the speed, acceleration of the knee seems to have improved (Wilcoxon test, $Z=2.022, \mathrm{p}<0.05$ ).

Regarding the time of appearance of the acceleration peak, the statistical analysis does not make it possible to show differences with regard to the sporting origin of the subjects (Mann-Whitney test, NS). Between T1 and T2, there is an evolution for the ankle (landmark 6), both for the wrestlers and the wrestlers-judokas (Wilcoxon test, $\mathrm{Z}=1.752,0.05<\mathrm{p}<0.10 ; \mathrm{Z}=2.022, \mathrm{p}<0.05)$.

\section{Discussion}

We showed, during the first evaluation, which postural attitudes of the two groups are different at the beginning from the movement at the end. The wrestlers without a previous judo experience adopt a postural attitude of low guard (bent on the legs, trunk inclined forwards) more marked than that of the subjects having a previous judo experience, the difference not being significant on the level of the cephalic segment. In addition, their trajectory during the movement is characterized by a slope of the trunk more marked towards the lower limb, which is bent at approximately $110^{\circ}$. This difference between the two groups cannot be explained by morphological characteristics (size, weight) since the two groups do not differ statistically compared to these variables. In addition $_{2}$ the two groups respected the instructions related to the finality of the movement, since the seizure of the support was carried out strictly on the same level.

In the group of wrestlers, the control of the adversary results in a direct seizure of this one. The low guard reducing the distance with the adversary allows a better stability by lowering the centre of gravity of the wrestler. The position of high guard upright ensures a lower stability because of the high position of the centre of gravity and the reduction of the basis of support [11]. Moreover, the rise in the guard is accompanied by a reduction of the defence possibilities and by an increase in muscular efforts in order to maintain a balance. The kinematic data from the study among wrestlers is in agreement with the realization of this technical gesture by experts [11].

To carry out the requested technique, judokas of origin seem influenced by their knowledge of the judo practice. In judo, guard position is high (compared to that of the wrestling) with a catch of the adversary's kimono jacket, which allows the mutual control of candidates $[12,13]$. The judoka's postural balance takes into account these high supports of hands on the adversary. The realization of the legs attack in the wrestler-judokas could be influenced by the "Moroté-Garé" technique in judo. It differs from the legs attack in wrestling concerning control sought by the adversary. In wrestling, it is at legs level, in judo the action is more carried towards thighs and basin, the starting position not allowing to reach very quickly lower areas of the body.

An explanatory hypothesis of these differences between the two groups of subjects could be the degree of expertise in wrestling. One can to a certain extent consider that the installation of posturo-kinetic coordinations supporting the movement required for experts "wrestlers" can be compared to beginners. Thus, Béraud and Gahéry showed, in the case of French boxing, a reorganization of posturo-kinetic coordinations that accompany the movement, under the effect of sport training [14]. Compared to this possible positive influence on the performance of the acquisition of new sensorimotor plannings during sport training $[4,15]$, the difference between the two groups of the study could be explained by a different use of sensory information following training, with a more selective and specific treatment at the expert subjects. The vision undoubtedly plays a very significant role, a possible attack appropriateness generally begin with a visual treatment from information, which could explain the rectified position of the head of the attacker. In the same way, Perrot [16] specified that the role of vision in the control of the static postural balance decreases with the expertise level, for karate experts and French boxing fighters.

Whatever the subjacent factor of training effects [17], in our study we could, to a certain extent, consider that wrestler-judokas are beginners concerning wrestling, which could explain postural differences with the other group ( 7 years of practice at least). An argument in favour of this explication is that we observe wrestler-judokas improving the realization of the movement when they are tested after the training period of ten weeks compared to the initial test. Nevertheless, if our results are compatible with this assumption, it is not possible now to uncover the mechanisms (motor programming, sensory data processing). This assumption must however be nuanced by the fact that these judokas subjects had a two years old practice of wrestling before the initial test and are thus not really beginners, even if they do not reach the expertise 
level of the other group.

The hypothesis of a negative transfer or an absence of transfer between both sport practices is also to explore. The existence of interference or absence of transfer between the two motor skills -judo and wrestling- are to be considered to explain the results [18]. Although this movement is a basic technique in training programs, the fact of having practised judo affects the postural attitudes of the subjects in the realization of this one. Moreover, this effect of the former practice of judo is particularly meaningful since these effects appear while at the same time these judokas have already made wrestling for two years. This is to be compared to the study of Travlos [19], which indicates that the increase of the number of training tests for a task can alter the transfer of learning on a new task. We can think that learning judo was accompanied, on the central organization level of the movement, by a "rigidification" of control. Thus, subjects with a previous experience in judo would have a good representation of the general goal of the action but not of the execution of the movement [20]. Bernstein points out that, with regard to the transfer abilities, a great confusion in the comprehension of the phenomenon comes from the fact that for a long time, the transfer was only considered through external similarity or composition of the movements [21]. According to him, the transfer is based on the use of previously acquired automatisms; these automatisms are not movements but corrections controlling the movement and its components. In other words, a transfer is manifested by the existence of groups of similar corrections at the level of the control of the movement. In other words, a transfer takes place by the existence of similar groups of corrections at the level of the control of the movement. From this perspective, we can also consider that the nervous processes of control would be different between these two fighting sports, which are the judo and the wrestling, compared to the movement to be carried out and that there would thus not have a possible positive transfer. Thus, although these two sport disciplines belong to the same group of combat sport, this work underlines the specificity of learning and indicates that acquisition of motor abilities in a speciality is not transferred inevitably in a positive way in another speciality of the same group.

\section{Acknowledgments:}

Acknowledgments for Professor Fancine THULLIER, UFRSTAPS, University of Caen, France, for her general support.

\section{Conflict of Interests}

No conflicts of interest have been stated by the authors.

\section{References}

1. Marrero-Gordillo N, Balius-Matas X, Vargas-Barneond JC, Carmona-Calero E, Perez-Ganzaleza H, Ramos-Gordillo AS, and al. O Soto Gari vs Perdelera. A descriptive kinematics study of a laboratory sample. Coaching and Sport Science Journal, 1998; 3(2): 39-46.

2. Proteau L, Tremblay L, DeJaeger D. Practice does not diminish the role of visual information in on-line control of a precision walking task: support for the specificity of practice hypothesis. Journal of Motor Behavior, 1998; 30: 143- 150. https://doi.org/10.1080/00222899809601331

3. Lee TD, Magill RA, Weeks DJ. Influence of practice schedule on testing schema theory predictions in adults. Journal of Motor Behavior, 1985; 17: 283- 299. https://doi.org/10.1080/00222895.1985.10735350

4. Perrot C, Deviterne D, Perrin P. Influence of training on postural and motor control in a combative sport. Journal of human movement studies, 1998; 35(3): 119-136.

5. Vuillerme N, Danion F, Marin L, Boyadjian A, Prieur JM, Weise I, Nougier V. The effect of expertise in gymnastics on postural control. Neuroscice Letters, 2001; 303: 83- 86. https://doi.org/10.1016/S0304-3940(01)01722-0

6. Mouchnino L, Aurenty R, Massion J, Pedotti A. Coordination between equilibrium and head-trunk orientation during leg movement: a new strategy built up by training. Journal of Neurophysiolgy, 1992; 67: 1587-98. https://doi.org/10.1152/jn.1992.67.6.1587

7. Massion J. Cerveau et motricité, fonctions sensori-motrices. [Brain and motor skills, sensory-motor functions]. Paris: Edition PUF; 1997. (In French)

8. Schmidt RA, and Young D. Transfer of movement control in motor learning. In S.M. Cormier and J.D. Hagman, eds., Transfer of learning: contemporary Research and Applications; San Diego California; 1987. https://doi.org/10.1016/B978-0-12-188950-0.50009-6
9. Magill RA. Motor Control (3rd edition). Wm. C. Brown; Dubuque Iowa; 1989.

10.Ferrari M. Influence of expertise on the intentional transfer of motor skill. Journal of Motor Behavior, 1999; 31: 79-85. https://doi.org/10.1080/00222899909601893

11.Petrov R. Lutte libre et lutte gréco-romaine [Free wrestling and greco-roman wrestling]. Edition de la Fédération internationale de luttes associées, Lausanne; 1984. (In French)

12.Barraud D, Brondani JC, Rousseau D. Médecine du judo [Judo medicine]. Paris: Masson; 1991. (In French)

13. Mesure S, Crémieux J, Amblard B. Les stratégies et performances posturales sensori-motrices: effet de l'entraînement [Postural sensory-motor strategies and performance: the effect of training]. Ann. Kinésithérapie, 1995; 22: 151-63. (In French)

14.Béraud P, Gahéry Y. Posturo-kinetic effects on kicking movements of a lack of initial ground support under the moving leg. Neuroscience Letters, 1997; 226: 5-8. https://doi.org/10.1016/S0304-3940(97)00202-4

15.Mesure S, Bonnet M, Crémieux, J. L'entraînement sportif peut-il avoir un effet général sur le contrôle postural statique? [Could sports training have general impact on static postural control]. Science et motricité, 1994; 21: 39-47. (In French)

16.Perrot C, Moes R, Deviterne D, Perrin P. Adaptations posturales lors de gestuelles spécifiques aux sports de combat. Science et motricité, 1998; 13: 64-74.

17.Mesure S, Crémieux J. Entraînement sportif et équilibre postural: performances, contrôle sensoriel et stratégies sensori-motrices [Sports training and postural balance: performance, sensory control and sensorymotor strategies]. 1998. (In French)

18.Lee TD, Simon D. Contextual interference. In" A. M. Williams, N. J. Hodges (Eds.), Skill Acquisition in sport: Research, theory and practice. London: UK, Routledge; 
2004. P. 29-44.

19.Travlovs AK. More practice does not necessarily enhance transfer of learning: evidence and interpretations. Perceptual and motor skills, 1999; 89: 2-3.
20.Decety J. The neurophysiological basis of motor imagery. Behavioral and Brain Research, 1996; 77: 45-52. https://doi.org/10.1016/0166-4328(95)00225-1

21.Bernstein NA. The coordination and regulation of movements. London: Pergamon Press; 1967.

\section{Information about the authors:}

Moufti H.; http://orcid.org/0000-0001-6421-1454; h_moufti@yahoo.fr; Royal Institute of Management training; National Center of Sports Moulay Rachid, Road of Meknes Km 12, Salé, Morocco.

Arfaoui A.; (Corresponding author); http://orcid.org/0000-0002-5705-2536; amine_arfaoui@yahoo.fr; Royal Institute of Management training; National Center of Sports Moulay Rachid, Road of Meknes Km 12, Salé, Morocco.

Cite this article as:

Moufti H, Arfaoui A. Kinematic analysis of the "attack to the legs" from wrestling: impact of prior judo expertise. Pedagogics, psychology, medical-biological problems of physical training and sports, 2019;23(1):19-23.

https://doi.org/10.15561/18189172.2019.0103

The electronic version of this article is the complete one and can be found online at: https://www.sportpedagogy.org.ua/index.php/PPS/issue/archive

This is an Open Access article distributed under the terms of the Creative Commons Attribution License, which permits unrestricted use, distribution, and reproduction in any medium, provided the original work is properly cited (http://creativecommons.org/licenses/by/4.0/deed.en).

Received: 30.09 .2018

Accepted: 29.10.2018; Published: 27.02.2019 